PAPER

\title{
Repeat microvascular decompression for hemifacial spasm
}

\author{
J A Engh, M Horowitz, L Burkhart, Y-F Chang, A Kassam
}

J Neurol Neurosurg Psychiatry 2005;76:1574-1580. doi: 10.1136/jnnp.2004.056861

See end of article for authors' affiliations .....................

Correspondence to: Dr Amin Kassam. University of Pittsburgh Medical Center, Center for Cranial Nerve Disorders, Suite B-400, 200 Lothrop Street, Pittsburgh, PA 15213, USA; kassamab@ upmc.edu

Received 23 October 2004 Revised version received 22 February 2005

Accepted 30 March 2005

\begin{abstract}
Objective: To report our experience with repeat microvascular decompression (MVD) for hemifacial spasm (HFS) in patients who have failed their first operation.

Methods: The authors describe 41 redo MVDs for HFS in 36 patients performed over a 3 year period. Seven patients underwent early re-operation after an aborted seventh nerve decompression. Eight patients underwent early re-operation for clinical failure. Eighteen patients underwent late re-operation for spasm recurrence long after their original MVD. Eight MVDs were performed on patients who had already undergone at least two prior operations.

Results: Twenty four patients experienced complete spasm resolution (70.6\%), eight patients had near total resolution $(23.5 \%)$, and two patients failed re-operation (5.9\%). Two patients were lost to follow up (5.6\%). A favourable outcome was reported by $82.4 \%$ of patients at a mean follow up interval of 18 months. A total of $91.7 \%$ of patients 50 years of age or younger were cured at follow up versus $59.1 \%$ of patients older than $50(p=0.04)$. Patients undergoing early re-operation were significantly more likely to be cured or improved than patients undergoing late re-operation $(p=0.03)$.

Conclusions: Repeat MVD for HFS is effective in experienced hands. Younger patients respond better to repeat MVD. Late repeat MVD for HFS is a reasonable treatment option, although results are less favourable than for early re-operation.
\end{abstract}

$\mathrm{H}$ emifacial spasm (HFS) is an infrequent disorder with an estimated yearly incidence of approximately 1 per $10000 .^{1}$ Although HFS is painless and benign in its course, the social stigma of the disease often causes significant patient distress. No effective medical therapy for HFS exists. Although botulinum toxin type A (Botox, Allergan, Irvine, CA) injections are minimally invasive, the benefits are temporary and the treatment is potentially disfiguring. Four decades ago, Gardner demonstrated that HFS is a surgically treatable condition. ${ }^{23}$ More than three decades ago, Jannetta began to popularise microvascular decompression (MVD) of the seventh nerve to treat HFS. This procedure has since evolved into the treatment of choice, with operative morbidities of $<10 \%$ and high rates of success reported in the literature. In experienced hands, spasm resolution rates immediately after MVD are greater than $90 \% .^{4-8}$ Over a 10 year follow up period, a 91\% excellent or partial success rate has been reported. ${ }^{4}$ However, patients who fail after MVD present a difficult clinical problem: having undergone a major operation, these patients nevertheless continue to suffer from HFS. A possible alternative for these patients is re-exploration and MVD, but the results of this operation are not well documented. This study represents our clinical experience with this relatively uncommon patient group.

\section{METHODS}

\section{Study population}

Over a 3 year period from January 2000 until December 2002, 39 patients underwent repeat MVD for HFS at the University of Pittsburgh Medical Center (UPMC). Of the 39 patients, 36 underwent procedures performed by the two senior authors (AK, MH); the remaining three patients were excluded from the study. Five of the 36 patients underwent more than one repeat MVD within the interval of the study, for a total of 41 operations. None of the 36 patients had HFS secondary to a mass lesion. No patients with facial myokymia, blepharospasm, or Meige syndrome were included. All patients had typical HFS characterised by symptoms originating from the orbicularis oculi and differing degrees of spread to the other periorbital and lower facial muscles. ${ }^{49}$ One patient had bilateral HFS. Sixteen patients had their first operation at UPMC, and 20 patients were referred to UPMC after prior operations elsewhere.

\section{Operative technique}

A previously described approach utilising lateral decubitus positioning, intraoperative microscopy, and Teflon pledgets for nerve decompression was employed. ${ }^{10}$ The treatment method of the two senior authors includes monitoring of brainstem auditory evoked responses and motor evoked potentials of the facial nerve by a specialised neurophysiology team. Following careful exposure of the seventh nerve-eighth nerve complex, any offending arteries or veins compressing the facial nerve anywhere from the brainstem to beyond the root exit zone are treated. The operation is complete when the nerve no longer demonstrates any visible evidence of vascular compression. In addition, ephaptic impulse transmission along the facial nerve must be obliterated in order to confirm an adequate decompression. Ephaptic transmission is judged to be eliminated once the "lateral spread" of impulses from one motor branch of the facial nerve to another is gone and cannot be elicited despite intraoperative facial nerve stimulation. ${ }^{11}$

Due to expected scarring of the subarachnoid cisterns among the late re-operation patients, a lumbar drain was placed pre-operatively to facilitate egress of cerebrospinal fluid as needed before and after dural opening. All patients had formal audiograms both pre- and post-operatively, and any patient with hoarseness or dysphagia had an endoscopic swallowing test and vocal cord evaluation prior to hospital discharge.

Abbreviations: AICA, anterior inferior cerebellar artery; EMG, electromyography; HBS, House-Brackmann score; HFS, hemifacial spasm; MVD, microvascular decompression; PICA, posterior inferior cerebellar artery; SAT, speech awareness threshold; UPMC, University of Pittsburgh Medical Center 
Table 1 Grading of quality of life measures after repeat MVD for HFS

\begin{tabular}{llll}
\hline $\begin{array}{l}\text { Ability to read } \\
\text { with affected } \\
\text { eye }\end{array}$ & $\begin{array}{l}\text { Lifestyle } \\
\text { restrictions }\end{array}$ & $\begin{array}{l}\text { Social } \\
\text { comfort }\end{array}$ \\
\hline 1 & No difficulty & $\begin{array}{l}\text { No restrictions } \\
\text { Less restriction } \\
\text { than pre-op } \\
\text { Same as pre-op }\end{array}$ & $\begin{array}{l}\text { No discomfort } \\
\text { Less discomfort } \\
\text { than pre-op } \\
\text { Same as pre-op }\end{array}$ \\
\hline 3 & Mild difficulty & Same as pre-op & \\
\hline
\end{tabular}

\section{Clinical follow up}

All intraoperative findings, surgical complications, and patient outcomes were recorded at the time of hospital discharge. Patients were brought back for a post-operative check up within 10 days and were carefully inspected for any evidence of residual spasm. Furthermore, all complications including cerebrospinal fluid leak, wound infection, facial weakness, hearing loss, and vocal cord dysfunction were recorded and treated. All patients were later contacted either by telephone or by electronic mail to complete a questionnaire regarding their clinical status. Neither of the senior operating surgeons was involved in the acquisition of long term follow up data. Data included presence or absence of residual spasm and overall quality of life since the operation. Patients with no residual spasm were deemed "cured". Patients with $25 \%$ or less of their pre-operative level of spasm were considered "improved". All patients with greater than $25 \%$ of their pre-operative level of spasm or hemifacial paresis of 4 or greater on the House-Brackmann scale s. $^{12}$ were regarded as "failed". Quality of life was determined by patients' ability to read with the affected eye, ability to work or maintain an active lifestyle, and level of comfort in social situations. In order to generate long term outcome measures, each of these variables was stratified according to patients' responses and given one of three grades as explained in table 1. This strategy was used in order to quantify overall patient outcomes, balancing degree of spasm with complication severity.

Using the criteria in table 1, patients were stratified into one of four outcome groups: excellent, good, fair, or poor. The "excellent" group was reserved for those patients who had no restrictions in any of the quality of life categories (that is, grade 1 in all four categories) following MVD. The "good" group consisted of those patients who were partially restricted in only one category (that is, grade 2 in one category, grade 1 in the others). The "fair" group was those patients who had suboptimal scores in multiple categories, but still retained better scores in all three categories. The "poor" group was those patients who were not improved in any or all of the three categories.

\section{Statistical methods}

All clinical data were evaluated for statistical significance. Each of the four patient groups was analysed separately, as well as all 36 patients as a whole. Categorical variables were analysed using $\chi^{2}$ testing. Continuous variables were analysed using ANOVA testing. p values of 0.05 or less were considered significant. Patients lost to follow up were excluded from clinical data analysis.

\section{RESULTS}

The 36 patients fell into the following groups. The first group consisted of those patients who had neurophysiological monitoring abnormalities during their first MVD which were significant enough to necessitate abortion of the procedure. These patients underwent a second stage operation within a
Table 2 Patient stratification according to timing of reoperation

\begin{tabular}{lll}
\hline Patient group & $\begin{array}{l}\text { Number of } \\
\text { patients }\end{array}$ & $\begin{array}{l}\text { Number of } \\
\text { procedures }\end{array}$ \\
\hline $\begin{array}{l}\text { Group 1: early re-operation } \\
\text { after first procedure aborted } \\
\text { Group 2: early re-operation } \\
\text { for failure }\end{array}$ & 7 & 7 \\
$\begin{array}{l}\text { Group 3: late re-operation } \\
\text { for failure }\end{array}$ & 18 & 8 \\
$\begin{array}{l}\text { Group 4: more than two } \\
\text { operations }\end{array}$ & $\begin{array}{l}7 \text { (4 patients also } \\
\text { listed in group 3) }\end{array}$ & 8 \\
Total & 36 & 41 \\
\hline $\begin{array}{l}\text { Four patients are members of both group 3 and group } 4 . \text { One patient in } \\
\text { group 4 underwent both a third and a fourth MVD during the study } \\
\text { period. This resulted in } 41 \text { operations for } 36 \text { patients. }\end{array}$
\end{tabular}

week of their original MVD. The second group of patients had significant post-operative spasm immediately following their first procedure or a significant recurrence in the immediate post-operative period. These patients underwent re-operation within 1 month of their original decompression. The third group of patients had recurrence of spasm more than 1 month after their original operation. Nearly all of these patients had their original procedure at another institution. The interval to repeat MVD ranged from 4 months to 12 years. The fourth group of patients required a third or fourth MVD during the study period; four of these seven patients were already part of group 3. Grouping of patients is summarised in table 2 .

\section{Early re-operation after aborted MVD (group 1)}

Group 1 consisted of seven patients in whom the first MVD had been aborted due to repeated neurophysiological monitoring abnormalities. Such abnormalities included amplitude reduction of brainstem auditory evoked responses by $>50 \%$ or signal latency of $>2 \mathrm{~ms}$ on three separate occasions. In the experience of the senior authors, these patients are at high risk of hearing loss if a fourth insult occurs during the same operation. All original operations and re-explorations for this group were performed by the senior authors (AK, MH). The MVD was not complete at the time of the monitoring abnormalities in any of the original operations. However, all patients had undergone some amount of arachnoidal dissection and Teflon felt deposition without a significant decrease in the lateral spread of impulses along the facial nerve. Therefore, these patients were brought back to the operating room within 1 week of the first procedure for a repeat attempt at MVD, that is, a second stage operation. None of the seven patients had a complication of their first procedure which necessitated delay of the second stage operation. Results for these patients are summarised in table 3.

The vascular pathology listed in table 3 refers to blood vessels partially decompressed during the first MVD and completely decompressed during the second stage procedure. All patients demonstrated complete obliteration of the lateral spread phenomenon at the conclusion of the second MVD.

The patients in the first group ranged from 39 to 63 years of age, with a mean age of 48.4 years. Four of the patients were female $(57.2 \%)$. Five of the seven patients were cured (71.4\%), and the other two patients had a near total resolution of spasm. One patient suffered a unilateral vocal cord paralysis. There were no operative deaths. There was no significant correlation between patient age and rate of spasm resolution in group $\mathrm{l}(\mathrm{p}=0.69)$. In addition, there was no significant correlation between patient sex and rate of spasm resolution $(\mathrm{p}=0.14)$. 
Table 3 Intraoperative findings and outcomes of MVD for HFS in patients whose first operation was aborted due to neurophysiological monitoring abnormalities

\begin{tabular}{lllllll}
\hline ID & Age & Sex & Vessel(s) treated & Spasm result & Quality of life & Complications \\
\hline 1 & 63 & F & PICA & Cured & Excellent & None \\
2 & 50 & M & AICA & Improved & Good & None \\
3 & 48 & F & PICA & Cured & Excellent & None \\
4 & 43 & M & Two veins & Cured & Excellent & Unilateral vocal cord paralysis \\
5 & 51 & M & Vertebral artery & Improved & Good & None \\
6 & 45 & F & AICA, vein & Cured & Excellent & None \\
7 & 39 & F & PICA & Cured & Excellent & None \\
\hline
\end{tabular}

All offending vessels are listed in the order in which they were treated. AICA, anterior inferior cerebellar artery; HFS, hemifacial spasm; MVD, microvascular decompression; PICA, posterior inferior cerebellar artery.

\section{Early re-operation for failure (group 2)}

Eight of the patients in this study underwent early reoperation for clinical failure. All eight of these patients had obliteration of the lateral spread of facial nerve impulses confirmed by neurophysiological monitoring during their first MVD. Nonetheless, all of these patients had significant post-operative spasm noted following their original procedure. All patients undergoing re-exploration demonstrated at least $20 \%$ of their original level of lateral spread of impulse transmission along the facial nerve on diagnostic electromyography (EMG) prior to repeat MVD. The interval between operations ranged from 4 to 19 days. None of the eight patients had a complication of their first MVD necessitating delay of the second operation. Intraoperative findings and clinical results for these eight patients are listed in table 4 .

The age range for group 2 was $27-80$ years, with a mean age of 52.9 years. All but one of the patients were female $(87.5 \%)$. Five of the eight patients $(62.5 \%)$ demonstrated complete post-operative resolution of their HFS, and the other three patients demonstrated significant improvement. One patient demonstrated mild increased hemifacial paresis $(12.5 \%)$. Two patients suffered unilateral hearing reduction (25\%). Two patients described mild balance difficulties following their operation (25\%), but both ambulate without assistance. One patient developed transient diplopia as a result of a sixth nerve paresis. Patient 15 suffered an inadvertent vertebral artery sacrifice during exposure and wound dissection, but developed no subsequent neurological dysfunction. Despite these complications, six of the eight patients $(75 \%)$ reported either an excellent or a good long term result. There were no operative deaths. In group 2, there was no significant correlation between patient age and cure rate $(p=0.66)$, or between patient sex and cure rate $(p=1.00)$. There was no significant difference in rate of spasm resolution between group $\mathrm{l}$ and group $2(\mathrm{p}=0.76)$.

During the first MVD, all patients had either anterior inferior cerebellar artery, posterior inferior cerebellar artery, or the vertebral artery identified as the source of compres- sion. Patient 15 had an unspecified vessel decompressed during the first operation. During the second operation, patients 14 and 15 had some modification of their original decompression to achieve resolution of lateral spreads. The remaining $75 \%$ of patients had other vessels decompressed. Coagulation and division of veins compressing the seventh nerve was performed in all but one case at re-exploration $(87.5 \%)$. There were no negative re-explorations.

\section{Late re-operation for failure (group 3)}

Eighteen patients underwent late re-operation for HFS between 4 months and 12 years after the original MVD. Ten of the patients $(55.5 \%)$ had suffered a recurrence of spasm following cure or near resolution, seven patients (38.8\%) had never experienced relief following the first MVD, and for one patient the information was unavailable. All but one of these patients had their first MVD at another institution; patient 21 had been treated at UPMC prior to the time interval of this study. Age range was 37-74 years, with a mean age of 52.9 years. Thirteen of the patients were women $(72.2 \%)$. One patient was lost to follow up. The decision to re-operate on these patients was made on the basis of clinical presentation; no diagnostic EMG was performed. Results are summarised in table 5.

After late re-operation, 11 patients were cured (64.7\%). Two additional patients had a significant decrease in their degree of spasm $(11.8 \%)$. A total of $76.5 \%$ of the patients were cured or significantly improved. Ten of the patients had an excellent outcome and two had a good outcome, accounting for $70.6 \%$ of the patients. Four patients $(23.5 \%)$ required a third operation for refractory symptoms. Patient 33 suffered an extracranial vertebral artery injury during the second operation which necessitated endovascular sacrifice of the vertebral artery. No intracranial opening was made. As a result of the vertebral artery sacrifice, the patient developed a lateral medullary syndrome with unilateral swallowing dysfunction, hoarseness, and facial numbness. The patient was maintained on anti-platelet therapy for 3 months and

Table 4 Outcomes of early repeat MVD for HFS in patients with persistent spasm following their first operation

\begin{tabular}{|c|c|c|c|c|c|c|c|}
\hline ID & Age & Sex & $\begin{array}{l}\text { Vessel (s) treated } \\
\text { at first MVD }\end{array}$ & $\begin{array}{l}\text { Additional vessel(s) } \\
\text { treated at second MVD }\end{array}$ & Spasm result & Quality of life & Complications \\
\hline 8 & 47 & $\mathrm{~F}$ & AICA & Vein & Improved & Good & HBS increased from 2 to 3 \\
\hline 9 & 80 & $\mathrm{~F}$ & $\mathrm{AICA}$ & Vein & Cured & Poor & Balance disorder, transient diplopia \\
\hline 10 & 50 & $\mathrm{~F}$ & Vertebral artery & AICA & Improved & Fair & $\begin{array}{l}\text { Unquantified partial hearing } \\
\text { loss, balance disorder }\end{array}$ \\
\hline 11 & 69 & $\mathrm{~F}$ & PICA & Two veins & Cured & Excellent & None \\
\hline 12 & 43 & $\mathrm{~F}$ & $\mathrm{AICA}$ & Vein, labyrinthine artery & Cured & Excellent & SAT increased from 18 to $33 \mathrm{~dB}$ \\
\hline 13 & 27 & $M$ & $\mathrm{AICA}$ & Small artery, vein & Cured & Excellent & None \\
\hline 14 & 54 & $\mathrm{~F}$ & $\begin{array}{l}\text { PICA with associated } \\
\text { arterial perforator }\end{array}$ & PICA, vein & Cured & Excellent & None \\
\hline 15 & 53 & $\mathrm{~F}$ & Unspecified artery & Unspecified artery, vein & Improved & Good & Vertebral artery sacrifice \\
\hline
\end{tabular}

All offending vessels are listed in the order in which they were treated. AICA, anterior inferior cerebellar artery; dB, decibels; HBS, House-Brackmann score; HFS, hemifacial spasm; MVD, microvascular decompression; PICA, posterior inferior cerebellar artery; SAT, speech awareness threshold. 
Table 5 Outcomes of late repeat MVD for HFS

\begin{tabular}{|c|c|c|c|c|c|c|c|}
\hline ID & Age & Sex & Interim to second MVD & Findings at second MVD & Spasm result & Quality of life & Complications \\
\hline 16 & 53 & $\mathrm{~F}$ & $\begin{array}{l}6 \text { years } \\
\text { (recurrence) }\end{array}$ & $\begin{array}{l}\text { Distal felt migration along } \\
\text { PICA loop }\end{array}$ & Improved & Fair & $\begin{array}{l}\text { Wound infection debrided } \\
1 \text { month post-operatively }\end{array}$ \\
\hline 17 & 65 & M & $\begin{array}{l}5 \text { years } \\
\text { (unknown) }\end{array}$ & $\begin{array}{l}\text { Distal felt migration along } \\
\text { PICA loop }\end{array}$ & $\begin{array}{l}\text { Lost to } \\
\text { follow up }\end{array}$ & Lost to follow up & None known \\
\hline 18 & 56 & $\mathrm{~F}$ & $\begin{array}{l}7 \text { months } \\
\text { (failure) }\end{array}$ & $\begin{array}{l}\text { AICA, PICA, significant } \\
\text { arachnoidal scarring, no } \\
\text { felt visualised }\end{array}$ & Cured & Good & HBS increased from 2 to 3 \\
\hline 19 & 48 & $\mathrm{~F}$ & 17 months (failure) & AICA, PICA, no felt visualised & Cured & Excellent & None \\
\hline 20 & 50 & $\mathrm{~F}$ & $\begin{array}{l}22 \text { months } \\
\text { (failure) }\end{array}$ & $\begin{array}{l}\text { Felt partially migrated along } \\
\text { PICA loop }\end{array}$ & Failed & $\begin{array}{l}\text { Underwent } \\
\text { third operation }\end{array}$ & None \\
\hline 21 & 54 & $\mathrm{~F}$ & $\begin{array}{l}5 \text { months } \\
\text { (recurrence) }\end{array}$ & $\begin{array}{l}\text { Vein decompressed, felt in } \\
\text { place on PICA }\end{array}$ & Improved & Good & Balance disorder \\
\hline 22 & 56 & $\mathrm{~F}$ & $\begin{array}{l}18 \text { months } \\
\text { (recurrence) }\end{array}$ & $\begin{array}{l}\text { AICA decompression } \\
\text { augmented, } 2 \text { veins treated }\end{array}$ & Failed & $\begin{array}{l}\text { Underwent } \\
\text { third operation }\end{array}$ & None \\
\hline 23 & 50 & $\mathrm{~F}$ & $\begin{array}{l}12 \text { months } \\
\text { (recurrence) }\end{array}$ & $\begin{array}{l}\text { PICA loop with felt in place, } \\
\text { augmented with more pledgets }\end{array}$ & Failed & $\begin{array}{l}\text { Underwent } \\
\text { third operation }\end{array}$ & None \\
\hline 24 & 57 & M & 4 months (failure) & Felt too distal on AICA & Cured & Excellent & None \\
\hline 25 & 48 & $\mathrm{~F}$ & $\begin{array}{l}10 \text { months } \\
\text { (recurrence) }\end{array}$ & $\begin{array}{l}\text { Felt well placed on AICA and } \\
\text { PICA. } 2 \text { veins and } 1 \text { arterial } \\
\text { perforator divided }\end{array}$ & Cured & Excellent & $\begin{array}{l}\text { Unilateral vocal cord } \\
\text { paralysis }\end{array}$ \\
\hline 26 & 56 & $\mathrm{~F}$ & $\begin{array}{l}8 \text { years } \\
\text { (failure) }\end{array}$ & $\begin{array}{l}\text { Vertebral artery and PICA } \\
\text { compressing CN } 7 \text { (no felt } \\
\text { visualised) }\end{array}$ & Cured & Excellent & None \\
\hline 27 & 71 & M & $\begin{array}{l}3 \text { years } \\
\text { (recurrence) }\end{array}$ & $\begin{array}{l}\text { Felt well placed on AICA, } \\
\text { vein divided }\end{array}$ & Cured & Excellent & None \\
\hline 28 & 37 & M & $\begin{array}{l}11 \text { months } \\
\text { (recurrence) }\end{array}$ & $\begin{array}{l}\text { Felt too distal on AICA } \\
\text { (repaired), vein divided }\end{array}$ & Cured & Excellent & None \\
\hline 29 & 39 & $\mathrm{~F}$ & $\begin{array}{l}6 \text { years } \\
\text { (failure) }\end{array}$ & $\begin{array}{l}\text { Unidentified artery } \\
\text { compressing CN 7, felt within } \\
7-8 \text { complex }\end{array}$ & Cured & Excellent & None \\
\hline 30 & 74 & $\mathrm{~F}$ & $\begin{array}{l}2 \text { years } \\
\text { (recurrence) }\end{array}$ & $\begin{array}{l}\text { Felt worn thin on AICA, vein } \\
\text { divided }\end{array}$ & Cured & Excellent & HBS increased from 2 to 3 \\
\hline 31 & 37 & $\mathrm{~F}$ & 1 year (failure) & Felt augmented on PICA & Cured & Excellent & None \\
\hline 32 & 56 & M & $\begin{array}{l}7 \text { years } \\
\text { (recurrence) }\end{array}$ & $\begin{array}{l}\text { Arachnoidal scar involving PICA } \\
\text { dissected, no felt visualised }\end{array}$ & Cured & Excellent & $\begin{array}{l}\text { HBS increased from } 2 \text { to } 3 \text {; } \\
\text { SAT increased from } 15 \text { to } \\
52 \mathrm{~dB}\end{array}$ \\
\hline 33 & 52 & $\mathrm{~F}$ & $\begin{array}{l}12 \text { years } \\
\text { (recurrence) }\end{array}$ & No intracranial opening & Failed & $\begin{array}{l}\text { Underwent } \\
\text { third operation }\end{array}$ & $\begin{array}{l}\text { Extracranial vertebral } \\
\text { artery injury requiring } \\
\text { endovascular sacrifice } \\
\text { and } 3 \text { months' anti- } \\
\text { coagulation }\end{array}$ \\
\hline
\end{tabular}

For patients with less than a 2 year interim between operations, the time period is rounded to the nearest month; otherwise, the interval is rounded to the nearest year. Patient 16 had bilateral HFS which was more severe on the treated side. Patient 21 was the only patient originally treated at UPMC. Findings at second MVD include visualisation of old felt pledgets and persistent offending vessels. AICA, anterior inferior cerebellar artery; CN 7, facial nerve; dB, decibels; HBS, HouseBrackmann score; HFS, hemifacial spasm; MVD, microvascular decompression; PICA, posterior inferior cerebellar artery. SAT, speech awareness threshold.

then underwent another retromastoid craniotomy, which is discussed in the results for group 4 .

Of the 17 patients who had an intracranial opening, six patients $(35 \%)$ demonstrated a misplaced or migrated pledget, seven patients required augmentation of a well placed pledget $(41 \%)$, and in four patients no felt was visualised $(24 \%)$. There were no negative re-explorations. Complication rates in the late re-operation group were as follows. Three patients had higher House-Brackmann facial paresis scores at follow up (17.6\%). None of these scores were greater than House-Brackmann 3. One patient suffered unilateral hearing reduction on audiometry (5.9\%). One patient developed a balance disorder $(5.9 \%)$ and one developed unilateral vocal cord paralysis $(5.9 \%)$. One patient developed a post-operative wound infection which required open debridement 1 month later $(5.9 \%)$. There were no procedure related deaths. Within group 3, there was no significant correlation between age and rate of spasm resolution $(p=0.97)$. Additionally, there was no correlation between sex and rate of spasm resolution $(p=0.24)$. Finally, no correlation was noted between the interval to re-operation and the rate of spasm resolution $(\mathrm{p}=0.59)$.

\section{Third MVD for HFS (group 4)}

Group 4 consisted of three patients referred from outside institutions following two failed MVDs for HFS and four patients from group 3 of this report. The results for this rare patient group are summarised in table 6. For the sake of brevity, intraoperative findings are not included.

One patient in this group was lost to follow up. Among the other patients, two had an excellent outcome, one had a good outcome, one had a fair outcome, and two had a poor outcome. Three patients were cured $(50.0 \%)$. There was no significant correlation between age or sex and rate of spasm resolution in this group. There were no operative deaths or negative re-explorations.

\section{Comprehensive results and complication rates}

A total of 41 procedures were performed on 36 patients. Age range was $27-80$ years, with a mean of 52.3 years. Twenty six of the patients were females $(72.2 \%)$. Twenty three of the patients had left sided spasm $(63.9 \%)$ and one patient $(2.8 \%)$ treated for left sided spasm had concomitant right sided spasm. Two patients were lost to follow up. A total of $61.5 \%$ of all procedures resulted in complete resolution of spasm, and $20.5 \%$ of all procedures resulted in partial resolution of spasm. Of 34 patients, 24 were cured at follow up (70.6\%), eight patients were improved $(23.5 \%)$, and two patients $(5.9 \%)$ were considered operative failures. A total of $94.1 \%$ of all patients had significant improvement of their HFS at a mean follow up interval of 18 months. Complication rates were as follows: unilateral partial hearing reduction $12.8 \%$, 
increased facial weakness $15.4 \%$, balance disorder $10.3 \%$, cerebrospinal fluid leak 2.6\%, sixth nerve palsy $5.1 \%$, unilateral vocal cord paralysis $12.8 \%$, wound infection $2.6 \%$, and vertebral artery sacrifice $5.1 \%$. There were no operative deaths.

Among all subjects, using patient age as a continuous variable, no correlation was found between patient age and rate of spasm resolution $(\mathrm{p}=0.97)$. However, when patients 50 years old or younger were compared to patients older than 50 , a significant correlation was discovered between young age and good outcome. At the end of the study, 11 of 12 patients who were 50 years of age or younger were cured (91.7\%). In contrast, 13 of 22 patients $(59.1 \%)$ more than 50 years of age were cured at follow up. This difference was statistically significant, indicating a positive correlation between younger age and cure rate after repeat MVD $(p=0.036)$. In contrast, six of nine men $(66.7 \%)$ demonstrated complete spasm resolution versus 18 of 25 women $(72.0 \%)$. This difference was not statistically significant $(\mathrm{p}=1.00)$.

The four patient subgroups were compared to determine if there were any significant differences among them in patient outcomes, as delineated in table 7 . The rate of spasm resolution was $71.4 \%$ in group $1,62.5 \%$ in group $2,64.7 \%$ in group 3, and $50.0 \%$ in group 4 . None of these differences were statistically significant $(\mathrm{p}=0.76)$. In addition, group 1 was compared to groups 2 and 3 collectively to see if patients undergoing a second MVD after procedural abortion were more likely to be improved than patients undergoing a second MVD for failure; no significant difference was found $(\mathrm{p}=0.55)$. Moreover, group 3 was compared to groups 1 and 2 collectively to see if late re-operation was less likely to be successful than early re-operation; all 15 early re-operations resulted in cure or significant improvement at follow up $(100 \%)$ versus 17 of 24 late re-operations $(70.8 \%)$. This difference was statistically significant $(p=0.03)$. However, there was no significant difference in overall complication rates among the four patient groups $(p=0.146)$, nor was there any significant difference in complication rates between any two specific groups compared directly to each other.

\section{DISCUSSION}

Much has been published regarding the high efficacy of MVD for HFS, with cure rates ranging anywhere from approximately 82 to $92 \%,{ }^{4-8}$ and excellent long term results 10 years after MVD in $84 \%$ of patients. ${ }^{4}$ However, little has been published regarding repeat MVD for HFS in those patients who fail their initial operation. Unlike patients with trigeminal neuralgia who have failed after MVD, these patients receive no relief from medications, percutaneous rhizotomy, or radiosurgery. As a result, these patients have three options: live with their disease, undergo Botox therapy, or undergo repeat MVD. For those who undergo repeat MVD, it appears that early re-explorations are more often successful than late re-explorations. In a brief correspondence from Fukushima, resolution of recurrent HFS is reported in 79 of 96 patients $(82 \%)$ after early re-operation for failure. ${ }^{13}$ In a more detailed analysis, Barker et al reported excellent results for 10 of 11 patients who had early re-operation for failure (91\%), but only $61 \%$ of 49 patients who had late re-operation for failure, including 10 patients who required a third operation. ${ }^{4}$ Finally, Kureshi and Wilkins reported complete relief in two of eight patients and partial relief in four of eight patients undergoing late re-exploration for HFS. ${ }^{14}$ The implication of these reports is that late repeat MVD is less effective than early repeat MVD. This was confirmed in our study: all early re-operations were successful versus $70.8 \%$ of late re-operations.

Despite the evidence that early repeat MVD is more effective than late repeat MVD, extreme caution should be taken prior to recommending re-operation for failure. Despite the high response rate among the patients in this study, over half the patients in this group suffered an operative complication. In addition, there is evidence that patients with persistent spasm after MVD improve with observation. Ishikawa et al reported that $90 \%$ of patients with residual post-operative spasm had resolution of their symptoms within 8 months. ${ }^{15}$ In addition, Gotu et al described immediate cure following MVD in $76.5 \%$ of cases, and a $91.6 \%$ cure rate at 1 year. ${ }^{16}$ Shin et al achieved an "excellent" result in $61.1 \%$ of patients 1 week after MVD, and in $82.7 \%$ of patients 6 months after MVD. ${ }^{17}$ Finally, Samii et al noted that 59\% of patients were spasm free at discharge, and $92.3 \%$ were spasm free 6 months after MVD. ${ }^{8}$ Clearly, there is strong evidence that patients not immediately cured following MVD are likely to be cured within a year without additional operations. The problem with this approach is that the patient has to accept refractory symptoms in the interim. Many patients have tremendous difficulty with this concept, since eventual cure cannot be guaranteed. In the practice of the senior authors $(\mathrm{MH}, \mathrm{AK})$, those patients with significant post-operative spasm who are uncomfortable with observational management undergo facial EMG. If the post-operative EMG shows absent or markedly reduced lateral spread of responses from the facial nerve ( $<20 \%$ of original lateral spread), the patient is not offered a repeat MVD. If the post-operative lateral spread phenomenon is significant, we usually offer reexploration, provided that the patient is well aware of the high risk of complications. There is no indication to immediately re-explore a patient with significant postoperative spasm and a markedly improved EMG.

An additional patient group described in this report is the patients who undergo early re-operation following procedural abortion, that is, a two stage MVD. The results for this group are favourable, including a $71.4 \%$ cure rate and a $100 \%$ rate of symptom improvement, with only one complication. The two

Table 6 Outcomes for patients undergoing a third MVD for recurrent HFS

\begin{tabular}{|c|c|c|c|c|c|}
\hline ID & Age & Sex & Spasm result & Quality of life & Complications \\
\hline 20 & 50 & $\mathrm{~F}$ & Lost to follow up & Lost to follow up & None known \\
\hline 22 & 57 & $\mathrm{~F}$ & Cured & Excellent & Transient sixth nerve palsy, CSF leak \\
\hline 23 & 50 & $\mathrm{~F}$ & Cured & Good & Unilateral vocal cord paralysis \\
\hline 33 & 53 & $\mathrm{~F}$ & $\begin{array}{l}\text { Grade } 5 \text { facial } \\
\text { paresis (failed) }\end{array}$ & Poor & $\begin{array}{l}\text { House-Brackmann } 5 \text { facial paresis, } \\
\text { unilateral deafness, balance disorder }\end{array}$ \\
\hline 34 & 62 & $\mathrm{~F}$ & Cured & Excellent & Unilateral hearing reduction \\
\hline 35 & 57 & M & $\begin{array}{l}\text { Grade } 6 \text { facial } \\
\text { paresis (failed) }\end{array}$ & Poor & $\begin{array}{l}\text { Underwent fourth MVD, developed } \\
\text { right facial paralysis }\end{array}$ \\
\hline 36 & 49 & $\mathrm{~F}$ & Improved & Fair & None \\
\hline
\end{tabular}

Patient 35 underwent both a third and a fourth MVD during the interval of the study. CSF, cerebrospinal fluid; HFS, hemifacial spasm; MVD, microvascular decompression. 


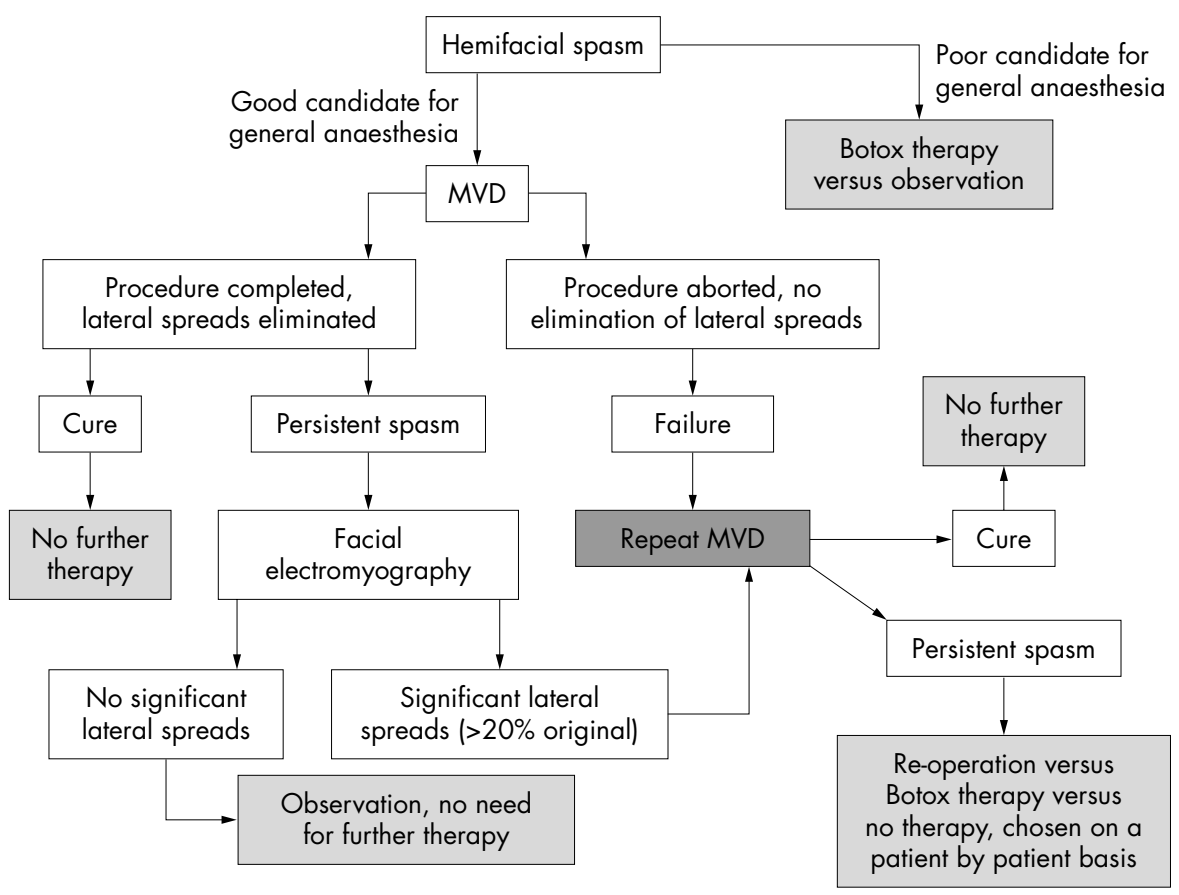

Figure 1 Treatment algorithm for HFS emphasising the role of repeat MVD. Botox, botulinum toxin; MVD, microvascular decompression. Treatment endpoints are delineated in light grey shaded boxes.

stage approach provides a relatively safe alternative to persistent manipulation of the eighth nerve during a difficult first time MVD; following the second operation, none of these patients exhibited a post-operative auditory deficit. There is no role for pre-operative EMG in this group, and observation is not effective. A summary of the treatment algorithm of the authors for patients with early spasm following MVD is summarised in fig 1 .

For patients who have late recurrences of HFS, reoperation is often successful, though significantly less effective than early re-operation $(p=0.03)$. Nevertheless, $76.5 \%$ of such patients were cured or improved in this report. Therefore, repeat MVD is a reasonable option in these patients. These operations demonstrate a high incidence of arachnoidal adhesions along the previously manipulated cranial nerves, which may account for the decreased efficacy of the procedure compared to early repeat MVD.

Age has not been found to be a significant predictor of outcome after MVD in previous large studies of HFS. ${ }^{46}$ However, this study indicates that age is a predictor of outcome after re-operation: among the 36 patients in this study, $91.7 \%$ of those who were 50 years of age or younger were cured at follow up versus $59.1 \%$ of those older than 50 years of age. The reason for this finding is unclear; perhaps older patients who have failed MVD are more likely to have chronic, irreversible neuropathy of the seventh nerve than younger patients. A post mortem study of patients with a history of HFS might be of value in answering this question. of note, male sex was found to be a predictor of positive outcomes in a prior study, ${ }^{4}$ but no such correlation was found in this review.

One of the weaknesses of this report is the relatively short follow up period, an average of 18 months. However, the frequency of post-operative spasm recurrence tends to decrease over time. It has been reported that patients who do not recur within 2 years of primary MVD have $<1 \%$ chance of having a recurrence at any time. ${ }^{18}$ For second MVDs, the results are less promising; a previous study reported that $61 \%$ of results were excellent immediately after re-operation but only $50 \%$ of results were excellent after 5 years, including $20 \%$ of the patients who required a third operation in the interim. ${ }^{4}$ Thus, the long term recurrence rates of patients who have undergone repeat MVD for HFS are probably higher than the recurrence rates of patients who have been cured by their first operation. Further research is required to determine the long term results of repeat MVD for HFS.

In conclusion, repeat MVD for HFS can be an effective procedure, although complication rates are probably higher than for first time procedures. Younger patients are significantly more likely to benefit from re-exploration. Patients who undergo early re-exploration are significantly more

Table 7 Comparison of patient outcomes as a function of operative group

\begin{tabular}{lcccc}
\hline & $\begin{array}{l}\text { Number of } \\
\text { patients }\end{array}$ & \% Cured & $\begin{array}{c}\text { \% Cured or } \\
\text { improved spasm }\end{array}$ & $\begin{array}{c}\text { \% Excellent or } \\
\text { good outcome }\end{array}$ \\
\hline Group 1: early repeat MVD for procedural abortion & 7 & $71.4 \%$ & $100 \%$ \\
Group 2: early repeat MVD for clinical failure & 8 & $62.5 \%$ & $100 \%$ \\
Group 3: late repeat MVD for clinical failure & 17 & $64.7 \%$ & $76.5 \%$ & $70 \%$ \\
Group 4: third or fourth MVD for HFS & 6 & $50.0 \%$ & $62.5 \%$ & $50.0 \%$ \\
\hline \multirow{2}{*}{ HFS, hemifacial spasm; MVD, microvascular decompression. Patients lost to follow up are not included. }
\end{tabular}


likely to be cured or improved than patients who undergo late re-exploration. A second MVD for HFS following an aborted first MVD is safe and effective. Patients experiencing early clinical failure should usually not undergo re-exploration, especially when improvement is seen on post-operative EMG.

\section{Authors' affiliations}

J A Engh, M Horowitz, L Burkhart, Y-F Chang, A Kassam, University of Pittsburgh Medical Center, Pittsburgh, PA, USA

Competing interests: none declared

\section{REFERENCES}

1 Auger RG, Whisnant JP. Hemifacial spasm in Rochester and Olmsted County, Minnesota, 1960 to 1984. Arch Neurol 1990;47:1233-4.

2 Gardner WJ. Concerning the mechanism of trigeminal neuralgia and hemifacial spasm. J Neurosurg 1962;19:947-58.

3 Gardner WJ, Sava GA. Hemifacial spasm-a reversible pathophysiologic state. J Neurosurg 1962;19:240-7.

4 Barker FG, Jannetta PJ, Bissonette DJ, et al. Microvascular decompression for hemifacial spasm. J Neurosurg 1995;82:201-10.

5 Fukushima T. Microvascular decompression for hemifacial spasm: results in 2870 cases. In: Carter LP, Spetzler RF, eds. Neurovascular surgery. New York: McGraw-Hill, 1995: 1133-45.

6 Huang $\mathrm{Cl}$, Chen $\mathrm{IH}$, Lee LS. Microvascular decompression for hemifacial spasm: analyses of operative findings and results in 310 patients. Neurosurgery 1991;30:53-6.
7 Loeser JD, Chen J. Hemifacial spasm: treatment by microsurgical facial nerve decompression. Neurosurgery 1983;13:141-5.

8 Samii M, Gunther T, laconetta G, et al. Microvascular decompression to treat hemifacial spasm: long-term results for a consecutive series of 143 patients. Neurosurgery 2002;50:712-8.

9 Jannetta PJ, Abbasy M, Maroon JC, et al. Etiology and definitive microsurgical treatment of hemifacial spasm: operative techniques and results in 47 patients. J Neurosurg 1977; 47:321-8.

10 McLaughlin MR, Jannetta PJ, Clyde BL, et al. Microvascular decompression of cranial nerves: lessons learned after 4400 operations. J Neurosurg 1999;90:1-8.

11 Moller AR, Jannetta PJ. Monitoring facial EMG responses during microvascular decompression operations for hemifacial spasm. J Neurosurg 1987;66:681-5.

12 House JW, Brackmann DE. Facial nerve grading system. Otolaryngol Head Neck Surg 1985;93(2):146-7.

13 Fukushima T. See "Comments" section of journal. Neurosurgery 1996;38:690.

14 Kureshi SA, Wilkins RH. Posterior fossa reexploration for persistent or recurrent trigeminal neuralgia or hemifacial spasm: surgical findings and therapeutic implications. Neurosurgery 1998:43:1111-7.

15 Ishikawa M, Nakanishi T, Takamiya Y, et al. Delayed resolution of residual hemifacial spasm after microvascular decompression operations. Neurosurgery 2001;49:847-54.

16 Gotu Y, Matsushima T, Natori Y, et al. Delayed effects of the microvascular decompression on hemifacial spasm: a retrospective study of 131 consecutive operated cases. Neurol Res 2002;24:296-300.

17 Shin JC, Chung UH, Kim YC, et al. Prospective study of microvascular decompression in hemifacial spasm. Neurosurgery 1997:40:730-5.

18 Payner TD, Tew JM. Recurrence of hemifacial spasm after microvascular decompression. Neurosurgery 1996;38:686-90. 